\title{
A Review and Comparison of Ship Power Simulation Methods
}

\author{
Maja Krčum \\ University of Split \\ Faculty of Maritime Studies \\ e-mail:mkrcum@pfst
}

\author{
Marko Zubčić \\ University of Split \\ Faculty of Maritime Studies \\ e-mail: mzubci@@pfst.hr
}

\author{
Anita Gudelj \\ University of Split \\ Faculty of Maritime Studies \\ e-mail:anita@pfst.hr
}

\author{
DOI 10.17818/NM/2018/4SI.22 \\ UDK 621.31:629.5 \\ Review \\ Paper accepted: 2. 10. 2018.
}

\begin{abstract}
Summary
Safe, secure and efficient clean sea shipping proposed by the IMO requires the development of the appropriate design, operating knowledge and tools for assessing energy efficient design and operation of ships. A brief overview of the methods and models of ship power management simulation shows the advantages and disadvantages of representative models. This review includes a comparison of different simulation methods, which implies different models, with the aim of optimizing the production of electricity on board, emission reductions and improved energy efficiency. In addition, the recommended technical solution for contributing to energy efficiency on board is given.
\end{abstract}

\author{
KEY WORDS \\ power management system \\ energy efficient \\ IMO
}

\section{INTRODUCTION}

Marine power systems are particularly complex when it comes to the application of high-voltage technologies or the application of renewable energy sources. This complexity, in relation to land systems, contributes to the complex ship's electrical power system where the production and consumption of electric power are one in place. It is not easy to test systems in real conditions, a series of simulations need to be done the best models for a particular type of vessel need to be chosen and the conditions determined in which the system is set up and designed. Different optimization solutions and different models lead to the optimum solution for a particular system.The proposed models depend on the particular interest of research in the field of ship engineering (navigation planning, renewable energy application, energy saving, energy management optimization, high voltage application, mechanical or electrical propulsion ...). Usually, models are used to: control the existing system, evaluate new designs, or re-install and optimize options.

Simulation of the various components of the ship power plant plays important role in the better understanding of the physical processes, as well as the interaction between the involved subsystems. In addition, simulation can be used to facilitate the development and optimization procedure of the ship power plant components by initially testing alternative design options, or to evaluate power plant subsystems control schemes. The simulation tools used throughout the design procedure of the power plant subsystems can be of varying complexity. Simulation models have, in many research fields, become the basic tool used in designing the system [13]. By observing seismic engineering, it can be said that there is no single approach to model building, mainly due to different applications and different settings in which simulation models are used.

By creating a mathematical model, specialists face certain problems. The real challenge is to determine where one's expertise ends, and where and when to include another expert.
The mutual compatibility of their areas of expertise can be problematic. The general trend in marine power energy and in other areas is the growing complexity and ratio of individual systems, which requires higher capacity and speed of PC (software and hardware). The modelling of the entire system is necessary for the team of experts, so each one creates for itself its own smaller model / subsystem. There are so many sets of models that represent a number of "black boxes" [4],[5] that need to be interconnected in an appropriate manner. From the point of view of modelling, concepts such as time scale, input and output, etc., are important, but the content of these "black boxes" is also significant. The purpose was obvious, for example, trying to optimize production, regulate the load or even make a proper load distribution between the generators. Some models also looked at the status of job failures as well as preventive actions to be taken. When setting up a model, we tried to answer some of the following questions:

Why is the simulation performed? - Due to the optimization of parameters, training, acquisition of skills, for further upgrading and testing ...

- Who will use the model? - It can be used by students, ship owners, research and development scientists, system designers, shipyards, equipment manufacturers ...

- To whom will the simulation results be presented? - They can be presented to the teacher / instructor, the equipment manufacturer, the rest of the working environment, ...

- What information is expected from the model? - There is a need for reduced fuel consumption, better choice of electronic devices, more efficient control and management system, ...

- How important is the decision made by the model? - The decision must be linked to the modelling system at the global or local level. If a model of a synchronous generator is in the power system, then every element of that model is 
important because it directly jeopardizes the production of electricity. It is therefore important to establish a working model algorithm.

Certainly, the evaluation of the model should also give the following answer:

- Is the maritime qualification level satisfactory? - To be able to see all the problems that are being simulated and affect the creation of a model, a part of the crew certainly requires more knowledge. For the crew, there is enough training.

- Are the simulation results correct and acceptable? - It is known that some parameters are neglected when creating a model. By neglecting the parameters, it is important to point out whether the results obtained by simulation are accurate and how accurate they are in reality. Namely, it is not enough that they are just accurate because in that case only a good image (copy) was made. It is also important for further upgrades and experiments for them to be new and cannot be measured and a bad model which is far from reality, later, when upgraded, would not produce results. Application of the model designs to the system incorporates real parameters or obtained from the manufacturer or downloaded from the website or from the existing project technical documentation (ship, shipyard, classification institution, owner...). Such extracts are guides for the creation of a credible model. Which way is hard to get such data, so it is used with various techniques that inevitably lead to poorer model quality.

- Should the developed model meet dynamic or static states? - Sometimes we only look at "linear" equations describing static states i.e. whether the fuse is ON or OFF function, whether the fuel valve is open or closed, but there are situations when transitional states are considered especially when it comes to electric propulsion and high (THD factor), are transient phenomena.

How long does the simulation last? - The simulation time of the process does not affect the quality of the model. It affects modellers because if too long a modeller is not ready to make frequent repetitions it reduces the quality of the model.

Is the model expensive?

\section{SHIP POWER MODELS}

\subsection{Designed models}

The simulator is used as a direct training method for connecting a synchronous generator to the network, regulating the parameters required for its connection. On the simulator, without fear of damage to the drive, it is possible to run a short circuit, overload el. networks, voltage drops, frequency stability, etc. There can, therefore, be only the maximum / minimum for conditions for a particular type of vessel, which means that a crew member/trainee can practice for proper states quite well. In short preparations ahead of the work on the simulator, you can get the answer to the question "What will happen if the load increases in the power grid?" So the simulator provides the possibility of good work under certain conditions but if the conclusion is that something should be changed in order to increase/drop voltage, setting another regulating element or something similar, it cannot give us a solution or a solution proposal. Special engine room simulator can be used as education tool, assessment tool, or education evaluation. The simulator is an [2] effective tool to foreseeing effects of any defectiveness in marine diesel engine.

The mathematical equations of the ship power plant model [6] can be implemented and solved by using the computational environment MATLAB Simulink ${ }^{\circledast}$. Hansen and Adnanes [6] have observed a changing of load / discharging in the ship's electrical network and impact on subsystems (diesel engine, synchronous generator, ship electric power, the synchronous motor in the function of electric propulsion and asynchronous motor as characteristic consumers). The diesel engine model had some deficiency e.g. air supply and exhaust gas temperature. The common variable for all generators was the voltage as a load function. The dynamic model for propellers is depicted by stationary equations describing the need for energy. The model is shown in vector form as a nonlinear model in the state space. Different loads are simulated. The purpose was to introduce new monitoring technologies to better manage the energy system. There is better workload in Simulink because there is a change in voltage and frequency, but we can use the data stored in a classic simulator and thus create a realistic picture of reality work if the parameters placed in the Simulink blocks are credible. To simulate the dynamics [3] of a system such as a marine power system in the graphics environment, Simulink works as a Matlab extension. Each element of the system or subsystems can be displayed in Matlab environment by using the appropriate blocks and as such to examine the end possibilities and connect and assemble them into a single model. On the good side, besides the usual simulations that can be used in the teaching process/education, they can also be used to select regulators, sources or consumers of electricity. Model of propulsion plan of merchant ship under various operating conditions in Matlab Simulink was simulated by G. P. Theotokatos [18].Thus, a simulation method can be used in designing, and an improved value can be provided e.g. by a regulator to the equipment manufacturer.

One of the approaches to studying and comprehending the entire ship energy system is the use of Matlab's Simscape platform. This platform enables modelling of mechanical, electrical, magnetic, hydraulic, pneumatic and thermal systems. What's important for complex systems such as a ship is that Simscape can easily integrate different systems. An example of a ship system model that is also an integral part of Matlab's documentation is shown in Figure 1.

Simscape platform can be used to study static and dynamic states of the system and thus optimize system components for one of the project variables. The ship's model is beneficial in the design stage of shipbuilding when deciding on the dimensions of equipment and space in which this equipment should be located. The model is also useful in the exploitation phase. During navigation, technical problems may arise in any part of the ship's system. If the problems are compounded or potentially caused by the interconnection of multiple systems then the model can be used as a tool to find and troubleshoot the problem. In the paper [17] the energy system of the ice going vessel was studied with the purpose of studying the energy efficiency of the system and storing various types of energy in different working regimes. Figure 2a shows the system studied in [17], while Figure $2 b$ shows an example of one of the subsystems implemented in Simscape. 




Source: https://www.mathworks.com/help/physmod/sps/examples/marine-full-electric-propulsion-power-system.html Figure 1 Example of a ship system in Simscape

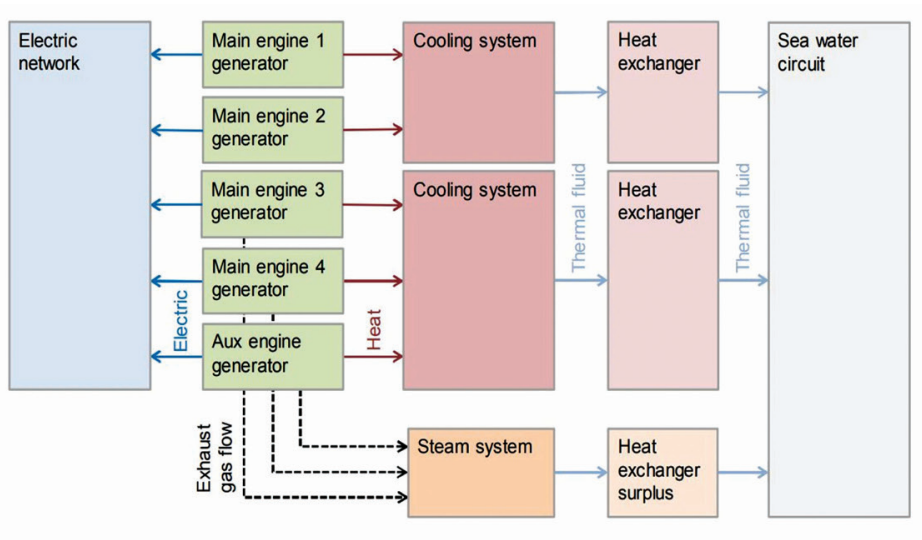

a

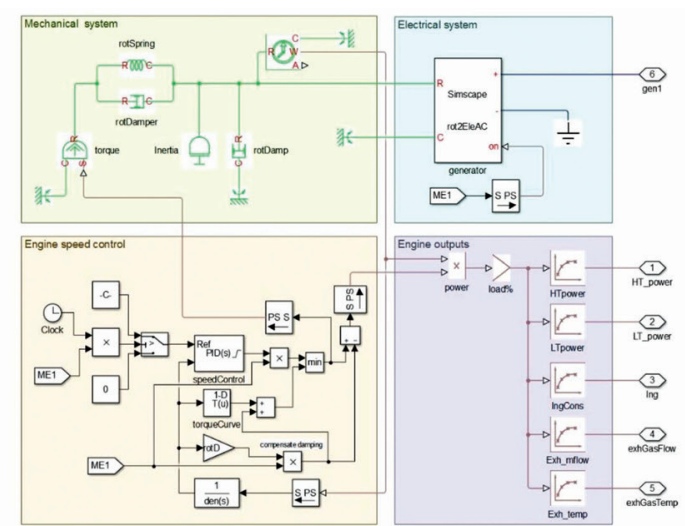

b

Source: https://www.mathworks.com/help/physmod/sps/examples/marine-full-electric-propulsion-power-system.html Figure 2 Example of a ship system in Simscape

\subsection{Control models}

Petri nets are suitable for describing and analysing a discrete event system whose features are asynchrony, distribution, parallelism and indeterminacy. Petri net is a graphical and mathematical tool adapted to the modelling of the main features of discrete event systems [15]. It is a bipartite graph consisting of two types of nodes (places and transitions), connected by arcs (edges). It allows the evaluation of a designed energy model interacting with environment conditions.

Wu et al. proposes a reconfiguration based on Petri's network for the renewal of the electro-energy system, with an emphasis on the estimate of the volume needed for the reconstruction of individual subsystems. He took into account the daily load and variations of consumers due to the increase in temperature in the electorate system. He applied it to the land tax and the question of whether it was justified on the ship system to apply such considerations. Dynamic programming is more pronounced in land-based power grids because they are radial, and such electric grids are less used in marine power systems.

In many research works, Multi-Agent Systems (MAS) were proposed to provide supports on power management, control power status, error detection and diagnosis microgrids and hybrid energy systems [4][8][9]. These research studies confirm that the MAS can effectively deal with complex energy management and hierarchical, distributed control of hybrid energy systems, mainly on land. According to the key electric component of ship power system, seven types of agents were proposed in [11]: generator agent, gas turbine agent, load agent, propelling system agent, breaker agent, switches agent and bus agent. The details on the agent's implementation were depicted by using Colored Petri Net (CPN). Also, the complete logistics chain of the control architecture was modelled by CPN, which connects effective agents for autonomous control of complex distributed systems with agents for the control of power management systems. Authors selected CPN as the modelling tool because CPN-based MAS models can support the simulation of the dynamic behaviour of the ship electrical system, engine room or Ship Bridge. The good system performance was demonstrated through the simulation.

In [12] authors presented the design of an information system for the management of the Photovoltaic -battery power system on a ship using software agents. In this study, energy sources were considered as agents and these agents 
were required to communicate and cooperate with each other according to the defined decision rules. The main design goal was to fulfil the load at a particular time by minimizing the use of diesel generators. Based on an analysis of the information flow of the data processing for making appropriate decisions and by combining the multi-agent system, algorithms and decision rules, the CPN model, for the switching process of power management system operating mode, was developed. Through the communication and cooperation between the proposed agents, unexpected conflicts can occur. So authors used the token driven mechanism in CPN to describe the event triggering mechanism of avoiding conflicts.

Knowledge-based systems (expert systems) can be applied to reconfigure the electrical system. It is a computer system that is programmed to mimic an expert to solve a particular problem. Artificial intelligence refers to the knowledge base that binds to a particular area. Expert systems can be used as well as on-line help for system operators that monitor and track a particular set of data. The design of ship automation is as proposed by Arent based on the experience of experts and represents a knowledge base that significantly contributes to the efficiency of not only the power system on board but also to others.

\subsection{Optimization models}

Amba [1] applied the genetic algorithm for complex electropower systems of warships to determine the optimal configuration of a power grid that quickly restores the power system without restriction of the operating system. Wolf and others advocate using the genetic algorithm that significantly contributes to the optimum design of the ship, where the optimization of the power system plays an important role.

In [13] authors analysed the problem of load regulation within the ship's electric power system and the final goal being the cost minimization. They applied the genetic algorithm to determine an adequate distribution of load with regard to the primary electric power sources in order to achieve optimum effects. The modulus of power calculations yields the data concerning voltages and losses which, together with other criteria, are used in the GA subsystem in order to conduct the optimisation, resulting in a set of solutions containing the appertaining quality evaluation.

Solar, wind, batteries and fuel cells are accepted as dependable and available renewable energy sources. It is possible to combine different renewable energy sources which can satisfy the load demand and to predict future system behaviour. Krčum, Gudelj and Tomas in research paper [10] used HOGA, simulation software which allows combining the system modelling and optimization with genetic algorithm (GA) in one framework, for optimal designing PV-Diesel-Battery system. Authors presented the multi-objective design of the hybrid PV-diesel system with battery storage, intended to minimize both the operation cost function and reduced $\mathrm{CO}_{2}$ emission by controlling the state of charge of the batteries.

The prediction of the navigation environment factors and working condition in order to maintain the engine speed is the key to optimization and control of the energy efficiency of the ship. Yan et al. [19] used neural network models which conducted the sensitivity analysis of the navigation environment factors on the energy efficiency of ships. The correlation between the environmental factors and the ship energy efficiency was demonstrated. Wavelet Neural Network (WNN) was used in [3] for the prediction of the navigation working condition. Moreover, to determine the optimal engine speed for the optimal energy efficiency under the predicted working condition authors established the real-time ship energy efficiency optimization model. The experimental results have showed that the proposed optimization model had a good effect on energy saving and emission reduction.

\section{CONCLUSION}

Based on the findings, from the analysis of marine power system, the opportunities offered by simulation models are diverse, comprehensive and developmental. The aim is to provide guidanceforfutureworktodevelopneworcomplementedmodels while respecting the development of newer technologies and the obligation to apply them. System modeling is most noticeable in Matlab-Simulink. All models, whether they include a primary starter (diesel engine, turbine), a synchronous generator or a consumer (asynchronous / asynchronous motor) have mathematical models. Depending on what we want to achieve by modeling, parameters can be more or less significant. Namely, in all models, there is no equal neglect. The quality model implies neglect but should know about them. Some parameters that were important in optimizing for a single element at the system level became less important, while some others gained significance. Whenever power system has complex energy management requirements a multi-agent system can be applied to model autonomous decision making entities, of the power plant on the ship, and solve the power dispatching problem by considering the suppliers and loads. Agents can operate without human intervention, they communicate and interact with other agents through the common language. Increased in some systems, it is necessary to identify different levels of the control system and organize them in a hierarchical control structure. In such systems, if we use only predefined agents for simulation, any restriction would have increased the amount of communication which reduces the flexibility of agent interaction, CPN based approach is proposed to enable agents to analyze whether the received load requirements can be supplied, whether the interaction can be accepted with the current status of the agent and whether the interaction conflicts with the objectives of the agent. GA gives good results when we want to optimize electricity consumption by optimizing fuel prices, i.e. the costs associated with the load, or just observe the emission of harmful gases. The simulator provides good results in the teaching process where it can be used for training and simulation of the process in real time, especially in critical times. Ultimately, the likelihood of the research will depend on the application of appropriate simulation models. Any deficiency in the system operation requires an analysis and is to be compared to what happens in reality and shipbuilders, engineers, boaters should be contacted along with anyone who can contribute to the better power system of the ship with their knowledge and skills. Research in this area should offer a greater number of possible solutions that will be more acceptable not only for shipowners, but also for end users, as well as for those who will or already use these systems. 


\section{REFERENCES}

[1] Amba,T., Butler-Purry, K. L., Falahi, M.: Genetic algorithm based damage control for shipboard power systems, in Proc. Electric Ship Technologies Symposium (ESTS), IEEE, 2009., pp. 242-252. https://doi.org/10.1109/ ESTS.2009.4906522

[2] Caglar, D.; Burak, Z.; Cengiz, D.: Usage of sımulator as an energy efficıent operation of maın engıne practıce, The 13th International Conference on Engine Room Simulators, Odessa - Ukraine, September 2017, pp 202- 218

[3] Chitsaz, H., Amjady, N., Zareipour, H.: Wind power forecast using wavelet neural network trained by improved Clonal selection algorithm. 2015. Energy Convers. Manage. 89 (1), pp. 588-598. https://doi.org/10.1016/j. enconman.2014.10.001

[4] Dou, C. X., Wang, W. G., Hao, D. W., Li, X. B.: MAS-based solution to energy management strategy of distributed generation system, Electrical Power and Energy Systems 69, 2015, pp. 354-366. https://doi.org/10.1016/j. ijepes.2015.01.026

[5] Grimmelius, H. T.: Simulation Models in Marine Engineering: From Training to Concept Exploration, COMPIT 2003; Hamburg

[6] Hansen, F. J.; Adnanes, A. K.; Fossen, T. I.: Mathematical Modelling of Diesel Electric Propulsion Systems for Marine Vessels, Mathematical and Computer Modelling of Dynamic Systems, Vol.7, No.1. pp. 1-33, 2001. https://doi. org/10.1076/mcmd.7.3.323.3641

[7] Jensen, K. , Kristensen, L. M. , Wells, L.: Colored Petri Nets and CPN Tools for Modelling and Validation of Concurrent Systems, International Journal On Software Tools for Tech. Transfer (STTT), Springer- Verlag, vol. 9, SpringerVerlag, 2007, pp. 213-254

[8] Jonban, M. S., Javidan, J., Akbarimajd A.: Designing A Multi-Agent Mechanism For Energy Management In A Photovoltaic System, International Research Journal of Applied and Basic Sciences, 2014, Vol. 8 (1) pp. 114-121

[9] Kai, W., Xinping Y., Yupeng Y., Feng, L.: Real-time optimization of ship energy efficiency based on the prediction technology of working condition, Transportation Research Part D: Transport and EnvironmentVolume 46, July 2016, pp 81-93
[10] Krčum, M., Gudelj, A., Tomas, V.: Optimal Design of Ships Hybrid Power system for Efficient Energy, Transaction on Maritime Science TOMS , doi.org/10.7225/ toms.v07.n01.002,2018., pp. 81-99. https://doi.org/10.7225/toms.v07. n01.002

[11] Krčum, M., Gudelj, A., Žižić , L.: Modelling of Power Management System on Ship by Using Petri Nets, Miscellaneous Problems in Maritime Navigation, Transport and Shipping / Weintrit, Adam ; Neumann, Tomas (ed.). Gdynia, Poland: Gdynia Maritime University, 2011. pp. 139-144.

[12] Krčum, M., Gudelj, A.: The Architecture of an Information system for th Power management System on Ship Transport Infrastructure and Systems / Dell'Acqua, Gianluca ; Wegman, Fred (ur.), London, UK: CRC Press Taylor \& Francis Group, 2017. pp. 953-958

[13] Krčum, M., Gudelj, A., Jurić, Z.: Genetic Algorithm Application in the Optimization of the Ship's Electric Power System Load, 10th IEEE International Conference on Methods and Models in Automation and Robotics Międzyzdroje, Poland, 2004. pp. 201-206

[14] Lu, D., Fakham, H., Zhou, T, François, B.: Application of Petri nets for the energy management of a photovoltaic based power station including storage units, Renew Energy 2010;35(6), pp. 1117-24. https://doi.org/10.1016/j. renene.2009.12.017

[15] Murata, T.: Petri nets: properties, analysis, and applications, in Proceedings of the IEEE, vol. 77, no. 4, pp. 541 - 580, 1989. https://doi.org/10.1109/5.24143

[16] Radan, D. Integrated Control of Marine Electrical Power Systems, Theses for degree of philosophy doctor, Department of Marine Technology, Norwegian University of Science and Technology, 2008.

[17] Rahkola, P., Kinnunen, A.: Ice going vessel energy system modelling and simulation, Ships energy efficiency technologies - now and the future, VTT Technical Research Centre of Finland Ltd, pp. 81-99.

[18] Theotokatos, G. P.: A Modelling Approach for the Overall Ship Propulsion Plant Simulation, 6th WSEAS International Conference on System science and simulation in engineering, Venice, Italy, November 21-23, 2007., pp 80-87

[19] Yan, X., Sun, X., Yin, Q.: Multiparameter sensitivity analysis of operational energy efficiency for inland river ships based on backpropagation neural network method. Marine Technology Society Journal, Volume 49, Number 1, January/February 2015, pp. 148-153. https://doi.org/10.4031/MTSJ.49.1.5 